\title{
GENÉTICA DA CONSERVAÇÃO DE Cabralea canjerana (Vell.) Mart. (Meliaceae) EM FRAGMENTOS FLORESTAIS DE MATA ATLÂNTICA NA APA FERNÃO DIAS ${ }^{1}$
}

Arthur Tavares de Oliveira Melo ${ }^{2}$, Alexandre Siqueira Guedes Coelho ${ }^{3}$, Marlei Ferreira Pereira ${ }^{4}$, Angel José Vieira Blanco ${ }^{4}$ e Edivani Villaron Franceschinelli ${ }^{5}$

\begin{abstract}
RESUMO - A Mata Atlântica é o bioma brasileiro mais severamente afetado pela fragmentação ambiental. A análise da estruturação da diversidade genética, assim como de características demográficas e quantitativas, permite inferir parâmetros populacionais importantes para os programas de conservação de espécies ameaçadas. Cabralea canjerana ssp. canjerana (Meliaceae) é uma espécie arbórea dioica considerada modelo para estudos de conservação da Mata Atlântica. Cento e oitenta e três indivíduos de oito subpopulações de C. canjerana foram coletados em fragmentos florestais na Área de Proteção Ambiental (APA) Fernão Dias, no Sul do Estado de Minas Gerais, Brasil. Utilizando marcadores microssatélites, a diversidade genética foi estimada e contrastada com medidas quantitativas e medidas geográficas dessas oito subpopulações. Elevados níveis de diversidade genética foram encontrados. Uma porção pequena, porém significativa, da variância genética total está estruturada entre as populações $(\theta=0,053)$, que foram estruturadas em dois grupos distintos. As estimativas dos níveis de diversidade genética nas populações localizadas acima de $1.800 \mathrm{~m}$ de altitude foram maiores, corroborando a importância dessas populações na manutenção da diversidade genética. A densidade populacional observada também foi maior nos fragmentos de maior altitude $(\mathrm{r}=0,849 ; \mathrm{p}$-valor $=0,007)$. Não houve correlação significativa entre as variáveis fenotípicas (altura dos indivíduos e diâmetro a 1,50 m acima do solo) e as medidas de diversidade genética. Esforços conservacionistas para que aumentem o fluxo gênico entre esses fragmentos florestais devem ser estimulados, principalmente entre os fragmentos de baixa altitude e os fragmentos de elevada altitude. É comprovado que populações situadas em elevadas altitudes possuem maior número de indivíduos por hectare e, portanto, maiores índices de diversidade genética. Essas áreas podem ser tratadas como repositório de diversidade genética, e sua manutenção é de extrema importância. O Código Florestal brasileiro determina que essas áreas acima de $1.800 \mathrm{~m}$ de altitudes sejam consideradas Áreas de Proteção Permanente (APP).
\end{abstract}

Palavras-chave: Mata Atlântica; Diversidade genética; Conservação biológica.

\section{CONSERVATION GENETICS OF Cabralea canjerana (Vell.) Mart. (Meliaceae) IN ATLANTIC FOREST FRAGMENTS OF FERNÃO DIAS EPA}

\begin{abstract}
The Atlantic Forest is the biome that is most severely affected by environmental fragmentation. The analysis of genetic diversity structure and demographic and quantitative characteristics allow us to estimate important population parameters to use in conservation programs of endangered species. Cabralea canjerana ssp. canjerana (Meliaceae) is a dioecious tree species that can be considered as a model for Atlantic Forest conservation studies. One hundred and eighty three individuals of eight C. canjerana subpopulations were randomly sampled in forests fragments of the Environmental Protection Area (EPA) Fernão Dias, in Southern Minas Gerais State, Brazil. Using microsatellite markers, the genetic diversity was estimated and contrasted
\end{abstract}

\footnotetext{
${ }^{1}$ Recebido em 21.01.2014 aceito para publicação em 09.12.2014.

${ }^{2}$ Universidade Federal de Goiás, Programa de Pós Graduação em Genética e Melhoramento de Plantas, Goiânia, Goiás, Brasil. E-mail: <arthurmelobio@gmail.com>.

${ }^{3}$ Universidade Federal de Goiás, Setor de Melhoramento de Plantas, Escola de Agronomia, Goiânia, Goiás, Brasil.

${ }^{4}$ Instituto Federal de Educação, Ciência e Tecnologia de Goiás, Goiânia, Goiás, Brasil.

${ }^{5}$ Universidade Federal de Goiás, Departamento de Botânica, Instituto de Ciências Biológicas, Goiânia, Goiás, Brasil.
}

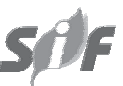

Revista Árvore, Viçosa-MG, v.39, n.2, p.365-374, 2015

http://dx.doi.org/10.1590/0100-67622015000200016 
with quantitative and geographic traits of these eight subpopulations. High levels of genetic diversity were found. A small, but significant, portion of the total genetic variance is structured among the subpopulations $(\theta=0.053)$, structured in two different groups. The estimates of the levels of genetic diversity were higher in populations above 1,800 meters of altitude, corroborating with the importance of these populations in the maintenance of genetic diversity. The population density observed was also higher in high altitude fragments ( $r=0.849 ; p$-value $=0.007)$. There was no significative correlation between phenotypic variables (height of individuals and stem diameter) and genetic diversity measures. Conservationist efforts that improve gene flow between these forest fragments must be stimulated, mainly between fragments of higher altitude and fragments of lower altitude. It is shown that populations located at high altitudes have a greater number of individuals per hectare and, therefore, higher levels of genetic diversity. These areas may be treated as repository of genetic diversity and its maintenance is extremely important. The Brazilian Forest Code determines that these areas above 1,800 meters altitude are considered as Permanent Protection Areas (PPA).

Keywords: Brazilian Atlantic Forest; Genetic diversity; Biological conservation.

\section{INTRODUÇÃO}

O Brasil é considerado pela comunidade acadêmica internacional como o país que detém a maior diversidade biológica do planeta, considerando ecossistemas, espécies, populações, indivíduos e genes (WILSON, 1998). Políticas públicas para a conservação desses recursos ainda são relativamente frágeis. A degradação ambiental dos ecossistemas em praticamente todos os biomas brasileiros acarreta perdas incalculáveis e irreversíveis à diversidade biológica (EHRLICH, 1998). O processo global de fragmentação de hábitats é, possivelmente, a mais profunda alteração causada pelo homem ao meio ambiente (WILSON, 1998). Esse processo possui influência direta na composição genética de uma população, podendo alterar os padrões de dispersão de pólens e sementes (GHAZOUL, 2005) e, consequentemente, os padrões de distribuição da diversidade genética dentro e entre as populações de uma espécie. Uma população submetida a essas condições sofre ação de uma série de fatores genéticos e estocásticos, como a redução do tamanho populacional efetivo, aumento intrapopulacional da endogamia e da deriva genética que, em poucas gerações, pode causar redução drástica do valor adaptativo dos indivíduos, diminuindo suas resistências a doenças e a adaptações a novas mudanças ambientais, aumentando, assim, a suscetibilidade da população a uma extinção local (YOUNG et al., 2001; LIENERT et al., 2002; FAHRIG, 2003; AVISE, 2010; CABALLERO et al., 2010). Muitos estudos têm discutido o efeito negativo da fragmentação de hábitat sobre a diversidade genética de espécies arbóreas com respeito, particularmente, ao bioma Mata Atlântica (SALGUEIRO et al., 2004; CONTE et al., 2008; TARAZZI et al., 2009; RIBEIRO et al., 2009).
Cabralea canjerana é uma espécie da família das Meliaceae formada por três subespécies (PENNINGTON et al., 1981; BARREIROS; SOUZA, 1986). Uma dessas subespécies, Cabralea canjerana ssp. canjerana, típica do bioma Mata Atlântica, é uma planta de porte arbóreo e ocorre em toda a região neotropical (PENNINGTON et al., 1981). O gênero Cabralea tem ampla distribuição desde a Costa Rica até o Norte da Argentina. No Brasil, esse gênero ocorre em várias regiões diferentes. $C$. canjerana ssp. canjerana é abundante entre o Sul do Estado de Minas Gerais e o Estado de Rio Grande do Sul, principalmente em florestas ombrófilas densas, estando ausente somente nas matas de araucárias (REITZ et al., 1983). Sua madeira é utilizada para construção civil e paisagismo (LORENZI, 1992), além de ser uma espécie indicada para uso em programas de recuperação de áreas degradadas (PEREIRA et al., 2011). O fruto de C. canjerana possui substâncias bioquímicas importantes que podem ser utilizadas no combate ao Trypanossoma cruzi, causador da doença-de-chagas (FOURNET et al., 1996).

O objetivo deste trabalho foi avaliar os índices de diversidade genética e medidas de caracteres quantitativos correlacionando-os com características geográficas de oito subpopulações de C. canjerana, para testar a hipótese nula de populações localizadas em áreas de elevada altitude são menos afetadas pela fragmentação ambiental, possuindo uma alteração menor nos padrões demográfico e na distribuição da variabilidade genética entre e dentro das populações. O presente estudo também tem como objetivo fornecer dados que possam orientar na definição de estratégias para conservação de áreas florestais do bioma Mata Atlântica.

Revista Árvore, Viçosa-MG, v.39, n.2, p.365-374, 2015 


\section{MATERIAL E MÉTODOS}

\subsection{Locais de coleta e procedimentos laboratoriais}

Os sítios de coleta estão localizados na Área de Proteção Ambiental (APA) Fernão Dias, numa região montanhosa no Sul do Estado de Minas Gerais, Brasil. A Área de Proteção Ambiental (APA) Fernão Dias está compreendida entre os paralelos 22 $30^{\prime} 13^{\prime \prime}$ e 22 $26^{\prime} 89^{\prime \prime}$

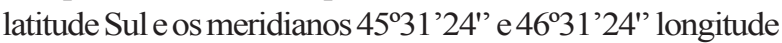
Oeste de Greenwich. Estende-se por oito municípios da região Sul de Minas Gerais, a saber: Toledo, Extrema, Camanducaia, Itapeva, Sapucaí-Mirim, Gonçalves, Paraisópolis e Brasópolis (IEF, 2008). A APA Fernão Dias foi criada em 1997 como medida compensatória para a construção da Rodovia BR-381 e atualmente ocupa uma área de cerca de 180 mil hectares. É cortada por dois importantes eixos viários: a BR-381 Rodovia Fernão Dias, que liga a capital mineira com a cidade de São Paulo; e a MG-173, que dá acesso aos municípios a leste da APA que conta com importantes cidades no contexto macrorregional, como Pouso Alegre (IEF, 2008). Na área de estudo, a Mata Atlântica foi floresta contínua até 1910, quando a atividade humana aumentou com a exploração madeireira inadequada por muitos anos, $\mathrm{o}$ que levou as fragmentações ambientais extensas. $\mathrm{O}$ desmatamento diminuiu após 1985, quando a exploração madeireira e a expansão da agricultura tornaram-se menos intensas devido à implementação de leis ambientais. A APA foi implementada em 1997 e atualmente vários fragmentos estão bem conservados, mas outros ainda estão sujeitos à exploração madeireira e ao desmatamento para fins agropecuários (AGUARI, 2001).

As amostras foram coletadas em quatro fragmentos florestais pequenos, em dois fragmentos de tamanho médio considerados corredores ecológicos e em dois fragmentos florestais grandes, numa área de mata contínua, totalizando oito sítios de coleta. Cada sítio foi considerado uma subpopulação. As distâncias entre essas subpopulações variam entre 0,38 e 4,10 km. As duas subpopulações localizadas em contínuos florestais estão distantes cerca de $2 \mathrm{~km}$ uma da outra e ambas possuem aproximadamente 4.000 ha de tamanho e estão situadas a mais de $1.800 \mathrm{~m}$ de altitude. Essas duas subpopulações estão em ambientes altamente preservados, onde não há evidência de exploração madeireira e atividade agropecuária. Os dois fragmentos medianos considerados corredores ecológicos estão bem preservados, porém há evidências de exploração madeireira. Essas duas subpopulações possuem tamanhos bem diferentes e estão a aproximadamente $1.600 \mathrm{~m}$ acima do nível do mar. A paisagem geográfica onde os outros quatro fragmentos florestais estão inseridos é composta por pequenas propriedades rurais com atividade agrícola, como o cultivo de batata e cenoura e a criação de animais para a atividade agropecuária. Esses fragmentos florestais possuem 5,5 ha de tamanho, em média, e estão localizados a $1.600 \mathrm{~m}$ de altitude.

Os dados quantitativos foram obtidos para as variáveis altura dos indivíduos e diâmetro a $1,50 \mathrm{~m}$ do solo (DAP), em 183 indivíduos amostrados de forma aleatória, nas oito subpopulações, com uma média de quase 24 indivíduos amostrados por subpopulação. Os dados geográficos estimados para cada uma das oito subpopulações foram: tamanho do fragmento florestal, densidade populacional, altitude/elevação e grau de isolamento. A variável grau de isolamento foi medida considerando a distância de todas as populações em relação ao maior fragmento florestal (Tabela 1).

Tecidos foliares desses indivíduos foram coletados para análise molecular. A extração de DNA genômico foi feita através do protocolo sugerido por Slotta et al. (2008). A genotipagem foi executadada por seis marcadores moleculares microssatélites descritos por Pereira et al. (2011), enquanto a eletroforese capilar foi realizada no analisador automático de DNA ABI3100, da Life Technologies, e a genotipagem, realizada pelo software GeneMapper 3.5.

\subsection{Análises estatísticas genéticas e morfológicas}

Duas medidas de diversidade genética foram estimadas: a heterozigosidade esperada $\left(\mathrm{H}_{\mathrm{E}}\right)$ - diversidade genética de Nei (1973); e a riqueza alélica $\left(A_{R}\right)$ fundamentada no método da rarefação. A estrutura genética das populações foi determinada pelos métodos de Weir e Cockerham (1984). As estatísticas descritivas como média e variância das medidas fenotípicas para cada uma das subpopulações foram estimadas pelo software R. Coeficientes de correlação de Pearson foram avaliados entre as medidas de diversidade genética $\left(\mathrm{H}_{\mathrm{E}} \mathrm{e} \mathrm{A}_{\mathrm{R}}\right)$, as duas medidas morfológicas e as quatro características demográficas das subpopulações, com o objetivo de correlacionar todas essas variáveis. Para identificar qual dessas variáveis fenotípicas e, ou, geográficas está mais relacionada com as medidas de diversidade genética, uma análise de regressão foi conduzida considerando as medidas de diversidade genética separadamente como 


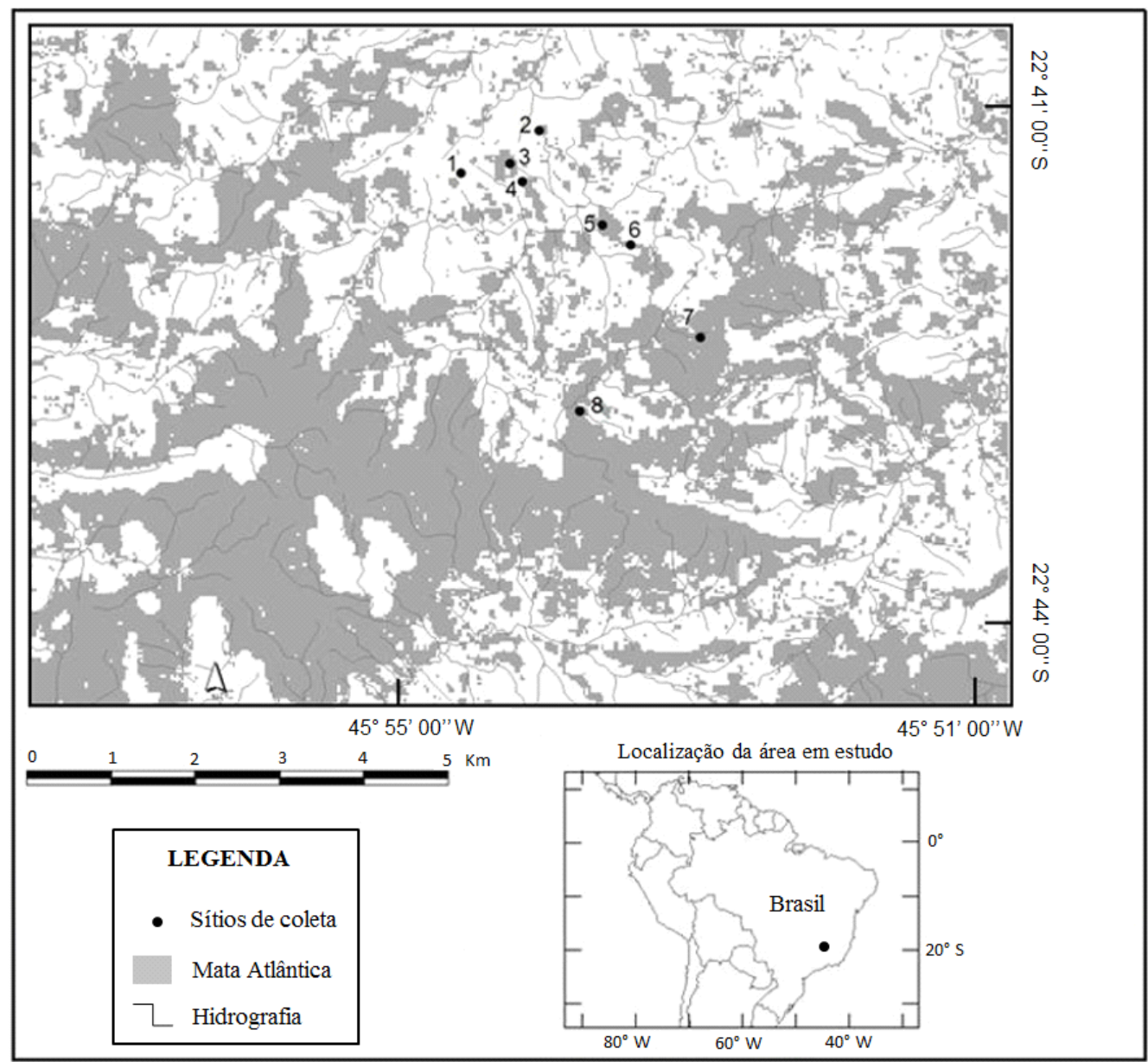

Figura 1 - Localização da APA Fernão Dias no Sul do Estado de Minas Gerais e os oito fragmentos florestais onde as amostras foram coletadas.

Figure 1 - Fernão Dias EPA localization in southeast of Minas Gerais State in Brazil and the eight forest fragments where individuals were sampled.

variável-resposta. Uma análise de agrupamento pelo método de UPGMA utilizando uma matriz de distância genética de Nei (1972) foi realizada pelo software R. Os nós de consistência do dendrograma foram avaliados pelo procedimento de bootstraps com $10^{4}$ passos iterativos no software Bood (COELHO, 2001).

\section{RESULTADOS}

\subsection{Caracterização e correlação dos parâmetros populacionais}

A diversidade genética média encontrada nessas oito subpopulações foi elevada $\left(H_{E}=0,724 ; A_{R}=6,545\right)$. A altura média dos indivíduos amostrados é de 7,8 m, enquanto o DAP médio é de $37,9 \mathrm{~cm}$. O número de indivíduos por hectare, isto é, a densidade populacional variou de 26 indivíduos na subpopulação 1 a 298 indivíduos, na subpopulação 8 (Tabela 1).

A correlação de Pearson entre as duas variáveis fenotípicas foi elevada e significativa $(r=0,710$; $p$-valor $=2,2{ }_{\mathrm{x}} 10^{-16}$ ), o que era de se esperar, pois quanto maior forem os indivíduos, maior será o diâmetro de espessura de seu tronco. A correlação entre a densidade populacional e as características geográficas como tamanho do fragmento florestal, altitude/elevação e distância entre as populações foi elevada e significativa a 5\% de índice de confiança (Tabela 2). Correlações elevadas e significativas também

Revista Árvore, Viçosa-MG, v.39, n.2, p.365-374, 2015 
foram encontradas entre as duas medidas de diversidade genética e a característica demográfica densidade populacional. Quando se correlacionam as medidas de diversidade genética com as características geográficas, há evidências de que fragmentos maiores $(\mathrm{r}=0,775$; $\mathrm{p}$-valor $=0,023)$, mais elevados $(r=0,692 ; \mathrm{p}$-valor $=0,056)$ e mais isolados $(r=-0,727 ; p$-valor $=0,040)$ apresentam maiores índices de diversidade genética. Ao correlacionar as variáveis fenotípicas (altura dos indivíduos e DAP) com as medidas de diversidade genética e densidade populacional, percebeu-se que não há correlação significativa entre estas medidas (Tabela 2). Há correlação muito forte da altura em que esses fragmentos florestais estão localizados e o seu tamanho $(\mathrm{r}=0,928$; $\mathrm{p}$-valor $=0,0008)$, mostrando claramente que áreas mais elevadas correm menos risco de exploração madeireira, mantendo elevado o número de indivíduos por hectare e, consequentemente, altos índices de diversidade genética (Figura 2). Na análise de regressão utilizando as medidas de diversidade genética como variávelresposta, nenhuma das outras seis variáveis geográficas e fenotípicas foi capaz de explicar a variação da diversidade genética entre as oito subpopulações. No entanto, as variáveis tamanho dos fragmentos e densidade populacional apresentaram-se mais relacionadas às medidas de diversidade genética por apresentarem maiores valores do teste de F utilizado na regressão, porém não significativos.

\subsection{A estrutura genética das populações e a distribuição da variabilidade genética}

Pequena porção, porém significativa da variância genética total, estimada com base na frequência dos alelos, está estruturada entre as populações $(\theta=0,053)$,

Tabela 1 - Características geográficas, genéticas e morfológicas das oito subpopulações de C. Canjerana. N é o número de indivíduos amostrados por subpopulação. $\mathrm{A}_{\mathrm{R}}$ e $\mathrm{H}_{\mathrm{E}}$ são as duas medidas de diversidade genética: riqueza alélica e heterozigosidade esperada, respectivamente.

Table 1 - Geographical, genetic and morphological characteristics of eight $\mathbf{C}$. canjerana subpopulations. $N$ is the number of individuals sampled by subpopulation. $A_{R}$ and $H_{E}$ are the two genetic diversity measures: allele richness and expected heterozigosity, respectively.

\begin{tabular}{|c|c|c|c|c|c|c|c|c|c|}
\hline Subpopulações & $\begin{array}{c}{ }^{\mathrm{a}} \text { Tamanho } \\
\text { (ha) }\end{array}$ & $\begin{array}{c}{ }^{\mathrm{b}} \text { Grau de } \\
\text { isolamento }(\mathrm{Km})\end{array}$ & $\begin{array}{c}\text { Altitude/ } \\
\text { Elevação(m) }\end{array}$ & $\begin{array}{c}\text { 'Densidade } \\
\text { populacional }\end{array}$ & $\mathbf{N}$ & $\mathbf{A}_{\mathrm{R}}$ & $\mathbf{H}_{\mathrm{E}}$ & Altura (m) & DAP (cm) \\
\hline Pop.01 & 0,90 & 4,08 & 1681 & 26 & 19 & 5,560 & 0,666 & 6,894 & 29,447 \\
\hline Pop.02 & 1,40 & 4,10 & 1667 & 76 & 19 & 6,370 & 0,736 & 9,710 & 52,516 \\
\hline Pop.03 & 12,00 & 3,89 & 1630 & 86 & 30 & 6,666 & 0,748 & 8,145 & 38,161 \\
\hline Pop.04 & 7,50 & 3,51 & 1603 & 86 & 30 & 5,486 & 0,682 & 7,666 & 41,500 \\
\hline Pop.05 & 15,00 & 2,92 & 1598 & 187 & 17 & 6,651 & 0,726 & 6,147 & 27,735 \\
\hline Pop.06 & 1,95 & 2,73 & 1600 & 67 & 09 & 6,238 & 0,713 & 7,000 & 31,333 \\
\hline Pop.07 & $4.000,00$ & 2,03 & 1810 & 221 & 38 & 7,272 & 0,749 & 9,589 & 32,948 \\
\hline Pop.08 & $4.000,00$ & 0,00 & 1928 & 298 & 29 & 7,391 & 0,778 & 7,275 & 49,826 \\
\hline Média & - & 2,907 & 1698,625 & - & 23,8 & 6,545 & 0.724 & 7,803 & 37,937 \\
\hline Variância & & - & - & - & - & - & - & 1,636 & 87,451 \\
\hline
\end{tabular}

${ }^{a}$ Medida em hectares, pela utilização de um GPS.

bDistância de uma subpopulação amostrada até o maior fragmento florestal (subpopulação 8).

c Número de plantas por hectare - R. M. Carmo - comunicação pessoal.

Tabela 2 - Correlações de Pearson entre as medidas de diversidade genética e as características demográficas e fenotípicas das subpopulações.

Table 2 - Pearson correlation among genetic diversity measures and demographic and phenotypic characteristics of the subpopulations.

\begin{tabular}{|c|c|c|c|c|c|c|c|c|c|c|c|c|}
\hline & \multicolumn{2}{|c|}{$\begin{array}{l}\text { Tamanho da } \\
\text { população }\end{array}$} & \multicolumn{2}{|c|}{$\begin{array}{l}\text { Altitude/ } \\
\text { Elevação }\end{array}$} & \multicolumn{2}{|c|}{$\begin{array}{c}\text { Densidade } \\
\text { populacional }\end{array}$} & \multicolumn{2}{|c|}{$\begin{array}{l}\text { Grau de } \\
\text { isolamento }\end{array}$} & \multicolumn{2}{|c|}{ Altura } & \multicolumn{2}{|c|}{ DAP } \\
\hline & $r$ & p-valor & $r$ & p-valor & $r$ & p-valor & $r$ & p-valor & $r$ & p-valor & $r$ & p-valor \\
\hline He & 0,649 & 0,081 & 0,621 & 0,099 & 0,758 & $0,029^{*}$ & $-0,651$ & 0,080 & 0,337 & 0,414 & 0,453 & 0,258 \\
\hline Ar & 0,775 & $0,023^{*}$ & 0,692 & 0,056 & 0,845 & $0,008^{* *}$ & $-0,727$ & $0,040^{*}$ & 0,266 & 0,522 & 0,207 & 0,622 \\
\hline De & 0,849 & $0,007^{* *}$ & 0,768 & $0,025^{*}$ & - & - & $-0,896$ & $0,002^{*}$ & 0,014 & 0,971 & 0,214 & 0,610 \\
\hline
\end{tabular}

* Estatisticamente significativo $(\mathrm{p}<0,05)$.

${ }^{* *}$ Estatisticamente significativo $(\mathrm{p}<0,01)$ 

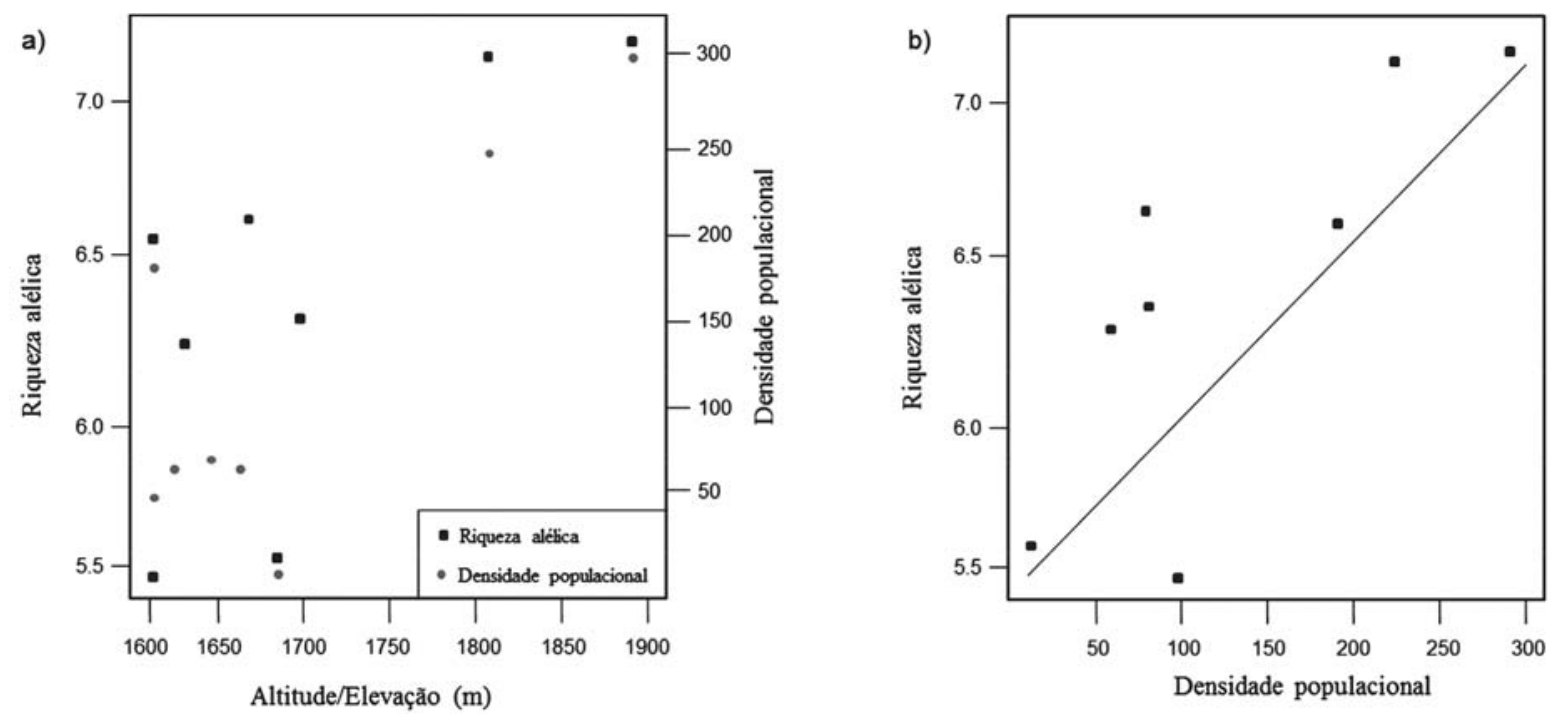

Figura 2 - Relação entre a altitude de elevação em que as subpopulações de C. canjerana estão situadas com a variável riqueza alélica e a densidade populacional. (a) A correlação de Pearson entre riqueza alélica e altitude foi $\boldsymbol{r}=$ $0,692$ ( $\mathrm{p}$-valor $=0,056)$ e entre a altitude e a densidade populacional, $\boldsymbol{r}=0,768(\mathrm{p}$-valor $=0,025)$. (b) A correlação de Pearson entre riqueza alélica e densidade populacional foi $\boldsymbol{r}=0,845$ ( $\mathrm{p}$-valor $=0,008$ ).

Figure 2 - Relation between elevation altitude in which C. canjerana subpopulations are situated with allelic richness and population density variables. (a) Pearson correlation between allelic richness and altitude was $\boldsymbol{r}=0.692(p$ value $=0.056$ ) and between altitude and population density was $\boldsymbol{r}=0.768$ ( $p$-value $=0.025)$. (b) Pearson correlations between allelic richness and population density was $\boldsymbol{r}=0.845$ ( $p$-value $=0.008)$.

o que é típico de espécies alógamas. O baixo índice de endogamia intrapopulacional $(\boldsymbol{f}=0,0513)$ corrobora a alogamia e a diocia da espécie. O dendrograma mostra que essas oito subpopulações estão estruturadas em dois grupos distintos. Um grupo A formado pelas subpopulações 1, 2, 3 e 4 e o grupo B formado pelas subpopulações 5, 6, 7 e 8 (Figura 3). É percebível também que os fragmentos que formam o grupo B estão a uma altitude maior em relação aos fragmentos que formam o grupo A. A média da altitude de localização das subpopulações que formam o grupo A é de $1.645 \mathrm{~m}$, enquanto para as subpopulações que formam o grupo $\mathrm{B}$, a média é de $1.734 \mathrm{~m}$ acima do nível do mar, uma diferença de aproximadamente $90 \mathrm{~m}$. Considerando os dois grupos separadamente, as estimativas de diversidade genética são muito maiores nas subpopulações do grupo B, em comparação com as subpopulações do grupo A. A média da riqueza alélica e da heterozigosidade esperada foram 6,020 e 0,708, respectivamente, nas subpopulações que compõem o grupo A, enquanto a média da riqueza alélica e a da heterozigosidade esperada foram 6,888 e 0,741 , nas subpopulações que compõem o grupo B.

\section{DISCUSSÕES}

\subsection{Esforços conservacionistas}

Esses resultados corroboram a hipótese de que os contínuos florestais da APA Fernão Dias, onde existem populações de C. canjerana em elevadas altitudes, apresentam maior quantidade de indivíduos jovens e adultos por hectare, os quais ainda preservam elevados níveis de diversidade genética. Considerando que esses fragmentos foram menos expostos às ações antrópicas, pode-se afirmar que desempenham hoje o papel de repositórios de diversidade genética. Um dos fatores que explicam essa manutenção de elevada diversidade genética nessas populações elevadas é a declividade geográfica do terreno. Essa declividade dificulta o acesso humano a áreas mais elevadas, dificultando o desmatamento.

Franceschinelli et al. (2007), trabalhando na mesma área com plantas jovens de Myrciaria floribunda, espécie arbórea comum na Mata Atlântica, encontraram elevados níveis de diversidade genética em fragmentos florestais grandes e pequenos. Os maiores fragmentos florestais

Revista Árvore, Viçosa-MG, v.39, n.2, p.365-374, 2015 


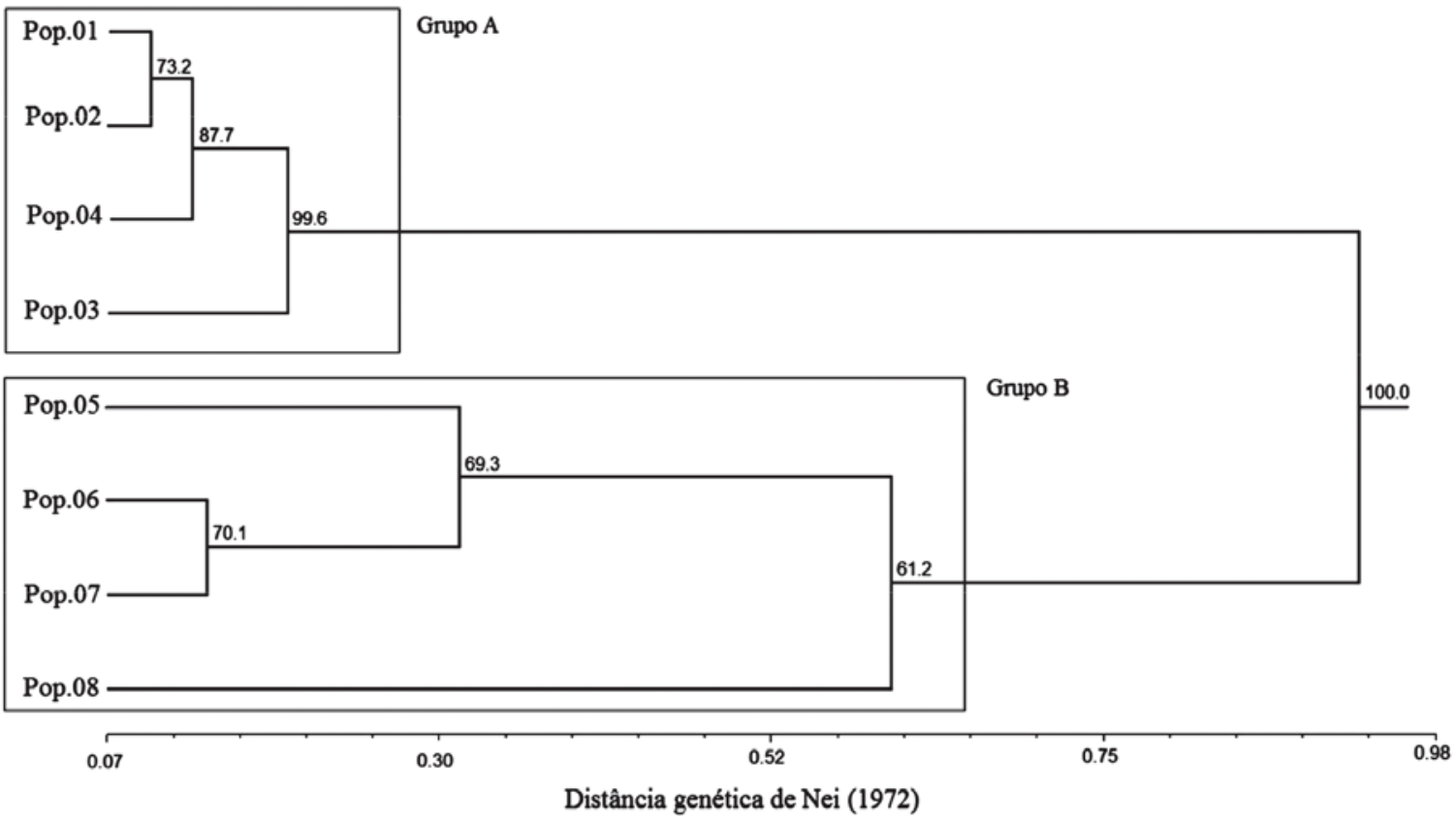

Figura 3 - Dendrograma das oito subpopulações de C. canjerana com os valores de consistência dos nós formados. Figure 3 - Dendrogram of the eight subpopulations of C. canjerana with nodes consistency values.

também estavam situados em regiões mais elevadas. No entanto, o que se percebe é um decaimento significativo da densidade populacional e da diversidade genética causada pela fragmentação de hábitats, tanto em espécies nativas (LIENERT et al., 2002; TOMIMATSU; OHARA, 2003; BACLES et al., 2006) quanto em espécies endêmicas (GONZALEZ-ASTORGA; NUNEZ-FARFAN, 2001; COLLEVATTI etal., 2001; DICK, 2001; SCHNEIDER et al., 2003).

Assim como no trabalho de Franceschinelli et al. (2007), este estudo encontrou altos índices de diversidade genética nos fragmentos florestais menores, mostrando a eficiência da Área de Proteção Ambiental (APA) Fernão Dias em manter e reestabelecer a diversidade genética dessas populações, nos últimos 17 anos, desde a sua implementação. Se a APA não tivesse sido implementada, com a rapidez com que os desmatamentos aconteciam na região, provavelmente os menores fragmentos florestais não existiriam mais (AGUARI, 2001).

A distribuição da diversidade genética entre populações de espécies arbóreas ao longo de um gradiente longitudinal pode ser afetada por processos neutros ou seletivos (SHI et al., 2011). Esses mesmos autores encontraram diferentes padrões da estrutura genética de populações de Castanopsis eyrei, em diferentes altitudes. Ohsawa et al. (2008) notaram um padrão diferente do que foi encontrado para C. canjerana, em populações de Quercus serrata, uma espécie de madeira economicamente importante, ao analisar 15 populações na montanha de Chichibu, no Japão. Para variações de altitudes entre 140 e $1.200 \mathrm{~m}$, esses autores encontraram menos diversidade genética em populações situadas em altitudes maiores, concluindo que a variação genética entre as populações tinha sido afetada pela topografia do local.

Melo et al. (2014), ao estudarem as mesmas populações de C. canjerana na APA Fernão Dias, mostraram que a endogamia intrapopulacional $\left(\mathrm{F}_{\mathrm{IS}}\right)$ apresentava forte correlação com os valores de densidade populacional. Essa correlação foi significativa, principalmente nas subpopulações maiores, situadas nos contínuos florestais. Considerando C. canjerana como uma espécie dioica, é provável que esse resultado reflita a existência de cruzamentos bi-parentais entre os indivíduos adultos, como consequência da estrutura especial de cada subpopulação.

Revista Árvore, Viçosa-MG, v.39, n.2, p.365-374, 2015 
Ambos os grupos indicados pelo dendrograma merecem atenção dos programas de conservação: os fragmentos florestais menores (o grupo A) possuem baixos índices de diversidade genética, por isso merecem atenção. Mas as subpopulações dos contínuos florestais (grupo B) também devem ser conservadas, pois são os alelos dessas subpopulações que têm a capacidade de, ao serem introduzidos nas subpopulações do grupo A, aumentar a diversidade genética dessas populações, favorecendo novas combinações alélicas e aumentando o valor adaptativo dos indivíduos nelas inseridos.

A falta de correlação entre as duas variáveis fenotípicas e as medidas de diversidade genética sugere que indivíduos adultos e jovens foram coletados em todos os fragmentos florestais e que as medidas de diversidade genética estimadas para essas subpopulações da APA Fernão Dias correspondem à diversidade genética existente nessas duas faixas etárias de indivíduos amostrados.

Os resultados apresentados para as subpopulações 7 e 8 , localizadas acima de $1.800 \mathrm{~m}$ de altitude, demonstram a eficiência das Áreas de Proteção Permanente (APP) em manter elevados níveis de densidade populacional e, consequentemente, altos valores de diversidade genética intrapopulacional. Com isso, pode-se discutir a importância de manter essas regiões acima de $1.800 \mathrm{~m}$ de altitude como Áreas de Proteção Permanente (APPs) protegidas por lei, algo que foi recentemente discutido no âmbito no Novo Código Florestal Brasileiro. É importante manter essas áreas protegidas por lei, pois, assim, haverá empecilho legal às ações humanas de exploração madeireira e agropecuária.

Os resultados mostrados das oito subpopulações de C. canjerana da APA Fernão Dias são evidências de como a fragmentação ambiental e as características geográficas locais podem influenciar a estruturação genética de populações de plantas arbóreas na Mata Atlântica, pois, considerando a ampla distribuição geográfica e as características de biologia reprodutiva, a C. canjerana pode ser considerada uma espéciemodelo para esse bioma. Os resultados deste trabalho também indicam a eficiência da estratégia de conservação in situ, em que nesse caso a implementação da APA teve papel importante na manutenção da diversidade genética, principalmente nos fragmentos florestais menores.

Revista Árvore, Viçosa-MG, v.39, n.2, p.365-374, 2015

\section{CONCLUSÕES}

É possível afirmar que a demarcação da APA Fernão Dias foi uma ação conservacionista importante, pois permitiu a manutenção da diversidade genética em subpopulações de C. canjerana. Conclui-se também que os fragmentos florestais mais elevados detêm maiores índices de densidade populacional e diversidade genética, consequentemente populações de espécies naturais localizadas acima de $1.800 \mathrm{~m}$ de altitude devem ser preservadas, porque são consideradas repositórios de variabilidade genética. A conservação legal dessas áreas elevadas é importante estratégia de conservação de populações naturais. Conhecimentos sobre os padrões de distribuição dos genótipos na paisagem geográfica são extremamente importantes para a conservação de recursos naturais, uma vez que esse conhecimento ajuda na definição de locais e estratégias de conservação in situ de espécies ameaçadas.

\section{AGRADECIMENTOS}

À International Conservation, pelo financiamento da pesquisa; também à L. F. Bandeira e à A. Y. Ciampi, pela colaboração no desenho dos primers; à E. C. Landau, pelo preparo do mapa da área da APA Fernão Dias; e à Coordenação de Aperfeiçoamento de Pessoal de Nível Superior (CAPES), por garantir a bolsa de mestrado ao primeiro autor.

\section{REFERÊNCIAS}

\section{AGUARI. Ações sociais para a preservação de fragmentos florestais na bacia do Rio Camanducaia. Camanducaia: Probio/MMA, 2001.}

AVISE, J.C. Perspective: conservation genetics enters the genomics era. Conservation Genetics, v.11, p.665-669, 2010.

BACLES, C.F.E.; LOEW, A.J.; ENNOS, R. A. Effective seed dispersal across a fragmented landscape. Science, v.311, n.5761, p. 628, 2006.

BARREIROS, H.D.S.; SOUZA, D.S.E. Notas geográficas e taxonômicas sobre Cabralea canjerana (Vell.) Mart. no Brasil (Meliaceae). Revista Brasileira de Biologia, v.46, n.1, p.17-26, 1986. 
CABALLERO, A.; RODRÍGUEZ-RAMILO, S.T.; ÁVILA, V.; FERNÁNDEZ, J. Management of genetic diversity on subdivided populations in conservation programmes. Conservation Genetics, v.11, p.409-419, 2010.

COELHO, A.S.G. Bood: Avaliação de dendrogramas baseada em estimativas de distancias/similaridades genéticas através do procedimento de bootstrap. Versão 3.0, 2001.

COLLEVATTI, R.G.; GRATTAPAGLIA, D.; HAY, J.D. Population genetic structure of the endangered tropical tree species Caryocar brasiliense, based on variability. Molecular Ecology, v.10, p.349-352, 2001.

CONTE, R.; REIS, M.S.; MANTOVANI, A.; VENCOVSKY, R. Genetic structure and mating system of Euterpe edulis Mart. populations: A comparative analysis using microsatellite and allozyme markers. Journal of Heredity, v.99, p.476-482, 2008.

DICK, C. Genetic rescue of remnant tropical trees by an alien pollinator. Proceedings of the Royal Society of London B -

Biological Science, v.268, p.2391-2396, 2001.

EHRLICH, P.R. The loss of diversity: Causes and consequences. In: WILSON, E.O. (Ed)

Biodiversity. Washington: National Academic Press, 1998. p.21-27.

FAHRIG, L. Effects of habitat fragmentation on biodiversity. Annual Review of Ecology, Evolution and Systematics, v.34, p.87-515, 2003.

FOURNET, A.; ROJAS, A.A.; CHARLES, B.; BRUNETON, J. Chemical constituents of essential oils of Muña, Bolivian plants traditionally used as pesticides, and their insecticidal properties against Chagas disease vectors. Journal of Ethnopharmacology, v.52, p.145-149, 1996

FRANCESCHINELLI, E.V.; VASCONCELOS, G.M.P.; LANDAU, E.C.; ONO, K.Y.; SANTOS, F.A.M. The genetic diversity of Myrciaria floribunda (Myrtaceae) in Atlantic forest fragments of different size. Journal of Tropical Ecology, v.23, p.361-367, 2007.
GHAZOUL, J. Pollen and seed dispersal among dispersed plants. Biological Review, v.80, p.413-443, 2005.

GONZALEZ-ASTORGA, J.; NUNEZ-FARFAN, J. Effect of habitat fragmentation on the genetic structure of the narrow endemic Brongniartia vazquezii. Evolution Ecology Research, v.3, p.861-872, 2001.

INSTITUTO ESTADUAL DE FLORESTAS - IEF. Plano de gestão da área de proteção ambiental Fernão Dias. Belo Horizonte: 2008.

LIENERT, J.; FISHER, M.; SCHNELLER, J.; DIEMER, M. Isozyme variability of the wetland specialist Swertia perennis (Gentianaceae) in relation to habitat size, isolation, and plant fitness. American Journal of Botany, v.89, p.801-811, 2002.

LORENZI, H. Árvores Brasileiras: manual de identificação e cultivo de plantas arbóreas nativas do Brasil. Nova Odessa:1992.

MELO, A.T.O.; COELHO, A.S.G.; PEREIRA, M.F.; BLANCO, A.J.V.; FRANCESCHINELLI, E.V. High genetic diversity and strong spatial genetic structure in Cabralea canjerana (Vell.) Mart. (Meliaceae): implications to Brazilian Atlantic Forest tree conservation. Natureza \& Conservação, v. 12, n. 2, p. 129-133, 2014.

NEI, M. Genetic distance between populations. The American Society of Naturalists, v.106, p.283-292, 1972.

NEI, M. Analysis of gene diversity in subdivided population. Proceedings of the National Academy of Sciences, v.70, p.3321-3323, 1973.

OHSAWA, T.; SAITO, Y.; SAWADA, H.; IDE, Y. Impact of altitude and topography on the genetic diversity of Quercus serrata populations in the Chichibu Mountains, central Japan. Flora, v.203, p.187-196, 2008.

PENNINGTON, T.D.; STYLES, B.D.; TAYLOR, D.A.H. Meliaceae. Flora Neotropica, v.28, p.235-244, 1981.

PEREIRA, M.F.; BANDEIRA, L.F.; BLANCO, A.J.V.; COELHO, A.S.G.; CIAMPI, A.Y.;

Revista Árvore, Viçosa-MG, v.39, n.2, p.365-374, 2015 
FRANCESCHINELLI, E.V. Isolation and characterization of microsatellite locis in Cabralea canjerana (Meliaceae). American Journal of Botany, v.98, n.1, p.1-3, 2011.

REITZ, R.; KLEIN, R.M.; REIS, A. Projeto Madeira do Rio Grande do Sul. Sellowia, v. 34/35, p. 1 $525,1983$.

RIBEIRO, M.C.; METZGER, J.P.; MARTENSEN, A.C.; PONZONI, F.J.; HIROTA, M.M. The

Brazilian Atlantic Forest: How much is left, and how is the remaining forest distributed? Implications for conservation. Biological Conservation, v.142, n.6, p.1141-1153, 2009.

SALGUEIRO, F.; FELIX, D.; CALDAS, J.F.; MARGIS-PINHEIRO, M.; MARGIS, R. Even population differentiation for maternal and biparental gene markers in Eugenia uniflora, a widely distributed species from the Brazilian coastal Atlantic rain forest. Diversity and Distributions, v.10, n.3, p.201-210, 2004.

SCHNEIDER, M.P.C.; BATISTA, C.G.; CARVALHO, D.; CERQUEIRA, R.; CIAMPI, A.Y.; FRANCESCHINELLI, E.V.; GENTILE, R.; GONÇALVES, E.C.; GRATIVAL,A.D.; NASCIMENTO, M.T.; POVO, A.R.; VASCONCELOS, G.M.P.; WAD, L.H.; WEIDERHECKER, H.R. Efeitos de fragmentação de hábitat na genética de populações naturais. In: RAMBALDI, D.; OLIVEIRA, D.A. (Ed.) Fragmentação de ecossistemas: causas, efeitos sobre a diversidade e recomendações de políticas públicas. Brasília: MMA/SBF, 2003.p.297-316.
SHI, M.M.; MICHALSKI, S.G.; CHEN, X.Y.; DURKA, W. Isolation by elevation: genetic structure at neutral and putatively non-neutral loci in a dominant tree of subtropical forests, Castanopsis eyrei. PLoS ONE, v.6, p.1-8, 2011.

SLOTTA, T.A.B.; BRADY, L.; CHAO, S. High throughput tissue preparation for large-scale genotyping experiments. Molecular Ecology Resource, v.8, n.1, p.83-87, 2008.

TARAZZI, R.; MANTOVANI, A.; REIS, M.S.

Fine-scale spatial genetic structure and allozymic diversity in natural populations of Ocotea catharinensis Mez. (Lauraceae). Conservation Genetics, v.11, n.3, p.965-976, 2009.

TOMIMATSU, H.; OHARA, M. Genetic diversity and local population structure of fragmented populations of Trillium camschatcense (Trilliaceae). Biological Conservation, v.109, p.249-258, 2003.

YOUNG, A.; BOYLE, T.; BROWN, T. The population genetic consequences of habitat fragmentation for plants. Trends in Ecology and Evolution, v.11, n.10, p.413-418, 2001.

WEIR, B.S.; COCKERHAM, C.C. Estimating Fstatistics for the analysis of population structure. Evolution, v.38, n.4, p.1358-1370, 1984.

WILSON, E.O. Biodiversity. Washington: National Academic Press, 1998. 